FULL-LENGTH ARTICLE

Manufacturing

\title{
A novel non-viral delivery method that enables efficient engineering of primary human T cells for ex vivo cell therapy applications
}

\author{
Heather Kavanagh*, Susan Dunne*, Darren S. Martin, Emily McFadden, Louise Gallagher, \\ Jessica Schwaber, Siobhán Leonard, Shirley O’Dea**
}

Avectas Ltd, Maynooth, Ireland

\section{A R T I C L E I N F O}

\section{Article History:}

Received 20 January 2021

Accepted 12 March 2021

\section{Key Words:}

non-viral delivery

Solupore

CAR T

CRISPR

CD19 CAR

TRAC

\begin{abstract}
A B S T R A C T
Background aims: Next-generation immune cell therapy products will require complex modifications using engineering technologies that can maintain high levels of cell functionality. Non-viral engineering methods have the potential to address limitations associated with viral vectors. However, while electroporation is the most widely used non-viral modality, concerns about its effects on cell functionality have led to the exploration of alternative approaches. Here the authors have examined the suitability of the Solupore non-viral delivery system for engineering primary human $\mathrm{T}$ cells for cell therapy applications.

Methods: The Solupore system was used to deliver messenger RNA (mRNA) and clustered regularly interspaced short palindromic repeats (CRISPR)/CRISPR-associated protein 9 (Cas9) guide RNA ribonucleoprotein (RNP) cargos to T cells, and efficiency was measured by flow cytometry. Cell perturbation was assessed by immune gene expression profiling, including an electroporation comparator. In vitro and in vivo cytotoxicity of chimeric antigen receptor (CAR) T cells generated using the Solupore system was evaluated using a realtime cellular impedance assay and a Raji-luciferase mouse tumor model, respectively.

Results: Efficient transfection was demonstrated through delivery of mRNA and CRISPR CAS9 RNP cargos individually, simultaneously and sequentially using the Solupore system while consistently maintaining high levels of cell viability. Gene expression profiling revealed minimal alteration in immune gene expression, demonstrating the low level of perturbation experienced by the cells during this transfection process. By contrast, electroporation resulted in substantial changes in immune gene expression in T cells. CAR T cells generated using the Solupore system exhibited efficient cytotoxicity against target cancer cells in vitro and in vivo. Conclusions: The Solupore system is a non-viral means of simply, rapidly and efficiently delivering cargos to primary human immune cells with retention of high cell viability and functionality.

(c) 2021 International Society for Cell \& Gene Therapy. Published by Elsevier Inc. This is an open access article under the CC BY-NC-ND license (http://creativecommons.org/licenses/by-nc-nd/4.0/)
\end{abstract}

\section{Introduction}

Autologous chimeric antigen receptor (CAR) $\mathrm{T}$ cell therapy has shown unprecedented efficacy as well as durable responses in cohorts of relapsed or refractory cancer patients with certain liquid tumors, resulting in several CAR T cell product approvals [1]. The proof of concept generated with these cell products is now driving significant levels of research, development and commercial activity in the ex vivo cell therapy field. Viral transduction has been the most widely used method for cell engineering, and these first approved CAR T cell therapies were engineered using viral vectors. However, the limitations of viral vectors

\footnotetext{
** Correspondence: Shirley O'Dea, PhD, Avectas Ltd, MaynoothWorks, Maynooth University, Maynooth W23 F2H6, Ireland.

* These authors contributed equally to this work.

E-mail address: sodea@avectas.com (S. O'Dea).
}

are well known. Specialized viral manufacturing processes combined with constraints on availability of manufacturing capacity make scaling to meet commercial demand a significant challenge [2]. The timeline from initiation of virus production to batch release of a Good Manufacturing Practice (GMP)-grade vector for cellular therapies can be lengthy and costly. Viral delivery systems are also susceptible to vector-mediated genotoxicity, such as random insertions that disrupt normal genes, accidental oncogene activation or insertional mutagenesis, leading to adverse immunogenicity and severe side effects [3]. In addition, constraints on the cargo packaging capacity of viral vectors are a further limitation on their applicability to the engineering of next-generation cell therapy products that will require complex modifications to successfully address solid tumors and for allogeneic products [4].

The scaling, cost and safety challenges associated with viral vectors have driven an interest in the development of non-viral 
alternatives. Greater multiplexing potential, flexibility and versatility to accommodate diverse cell types and accelerated manufacturing timelines, all while avoiding the manufacturing challenges, side effects and regulatory burden associated with viral vectors, are attractive attributes in any one intracellular delivery method [5]. Non-viral intracellular delivery methods can be broadly classified into two main categories. The first includes physical/mechanical methods such as electroporation, sonoporation, magnetofection, gene gun, microinjection and cell squeezing [6-8]. However, many of these methods are unsuited to cell therapy manufacturing processes. The second category includes chemical vectors such as cationic polymers and lipids, including lipid nanoparticles, but to date the efficiency of these chemical methods in primary immune cells is low and toxicity remains a concern [9-11]. As a result, electroporation platforms are currently the most widely used non-viral technologies for cell engineering. During electroporation, target cells are placed in a conductive buffer and an electrical potential is applied, leading to the formation of pores in the plasma membrane [6]. Cargos present in the culture medium can pass through these pores into the cell. Typically, electroporation devices utilize different buffer compositions, electrical field strengths and pulse durations to optimize delivery and maximize cell viability post-process.

Next-generation immune cell products are likely to be both virally and non-virally modified. For example, the first human trial to test the safety of clustered regularly interspaced short palindromic repeats (CRISPR)/CRISPR-associated protein 9 (Cas9) gene editing of T cells employed electroporation to deliver ribonucleoproteins (RNPs) targeting three genes prior to viral transduction to express the NYESO-1 T cell receptor [12]. However, concerns persist regarding the impact of the electroporation process on immune cells, with reports of sustained intracellular calcium levels, changes in gene expression profiles, reduced proliferative capacity and decreased potency $[8,13,14]$. It has become clear that robust immune cell proliferation and effector function in vitro correlate with improved anti-tumor function in vivo, highlighting the need for delivery methods that do not negatively impact these critical quality attributes of the effector cells $[15,16]$. In addition, to ensure that manufacturing is feasible in terms of cost, time and meeting the urgent clinical need, it is critical to achieve sufficient yields of viable transgene-positive cells to produce a final product to treat patients. Therefore, alternative approaches are required and the ideal intracellular delivery method will allow transfection of a diverse array of cargo to multiple cell types while minimally perturbing normal cell function.

The authors previously reported on a non-viral method using the Solupore system that allows for transient permeabilization of the cell membrane to achieve rapid intracellular delivery of cargos with varying compositions, properties and sizes, such as macromolecules and nucleic acids [17]. During the delivery process, the cargo of interest is mixed with a delivery solution that contains a low concentration of ethanol as a cell permeabilizing agent. Target cells are placed into the Solupore system, culture medium is removed and the delivery solution is applied to the cells in the form of droplets. The volume and size of the droplets are precisely controlled to maximize cargo delivery and cell recovery post-process. After a brief incubation, culture medium is added to the cells and they are removed from the system. Here it is demonstrated that the Solupore system can successfully facilitate the delivery of messenger RNA (mRNA) and gene-editing tools such as CRISPR-Cas9 to primary human T cells with minimal perturbation of cell function.

\section{Methods}

Ethics

All experimental methods were carried out in accordance with the approved guidelines. Leukopaks from healthy donors were sourced from AllCells (Quincy, MA, USA) or BioIVT (Westbury, NY, USA) in full compliance with Good Clinical Practice as defined under US Food and Drug Administration and US Department of Health and Human Services regulations and International Council for Harmonisation of Technical Requirements for Pharmaceuticals for Human Use guidelines. The murine CAR T cell efficacy study was performed at The Jackson Laboratory, an AAALAC International-accredited and Office of Laboratory Animal Welfare-assured institution. The Jackson Laboratory adheres to all applicable international, national and institutional policies for the care and use of research animals. All experimental procedures were approved by the Institutional Animal Care and Use Committee of The Jackson Laboratory.

\section{Cell isolation and culture}

Peripheral blood mononuclear cells (PBMC) were isolated from fresh leukopaks using Lymphoprep density gradient medium (STEMCELL Technologies, Vancouver, Canada) and cryopreserved using standard methods. Upon thaw, T cells were isolated from PBMC using soluble CD3 (clone OKT3) and CD28 (clone 15E8) antibodies (Miltenyi Biotec, Bergisch Gladbach, Germany), each at $100 \mathrm{ng} / \mathrm{mL}$. Cells were initiated for 3 days in complete culture medium consisting of CTS OpTmizer plus supplement (Gibco, Waltham, MA, USA) with 5\% Physiologix serum replacement (Nucleus Biologics, San Diego, CA, USA), 1\% L-glutamine and $250 \mathrm{IU} / \mathrm{mL}$ IL-2 (CellGenix, Freiburg, Germany). Cell viability was measured using a 4',6-diamidino-2-phenylindole/Acridine Orange viability stain with the Via1-Cassette and NucleoCounter NC-3000 (ChemoMetec, Allerod, Denmark).

\section{Transfection using the Solupore system}

The transfection method was adapted from that previously described [17]. Cells were transferred to either 96-well filter bottom plates (Agilent Technologies, Santa Clara, CA, USA) at $3.5 \times 10^{5}$ cells per well or to transfection pods (Avectas, Maynooth, Ireland) at $6 \times 10^{6}$ cells per pod. Culture medium was removed from the 96well plates by centrifugation at $350 \times \mathrm{g}$ for 120 seconds and from the pods by gravity flow. Cargos were combined with delivery solution (32.5 mM sucrose, $106 \mathrm{mM}$ potassium chloride, $5 \mathrm{mM} \mathrm{N}$-2-hydroxyethylpiperazine-N-ethanesulfonic acid in water) and $1 \mu \mathrm{L}$ and $50 \mu \mathrm{L}$ were delivered to the cells in the 96-well plates and pods, respectively. For delivery of RNP and mRNA, delivery solution also contained $10 \%$ and $12 \% \mathrm{v} / \mathrm{v}$ ethanol, respectively. Following a 30 -second incubation at room temperature, $50-2000 \mu \mathrm{L} 0.5 \times$ phosphate-buffered saline solution $(68.4 \mathrm{mM}$ sodium chloride, $1.3 \mathrm{mM}$ potassium chloride, $4.0 \mathrm{mM}$ sodium hydrogen phosphate, $0.7 \mathrm{mM}$ potassium dihydrogen phosphate) was added, and after 30 seconds, complete culture medium was added.

\section{Electroporation}

Cells were electroporated with the 4D-Nucleofector system (Lonza, Basel, Switzerland) using either the $20-\mu \mathrm{L}$ or $100-\mu \mathrm{L}$ Nucleocuvette format as per the manufacturer's protocol with the P3 Primary Cell 4D-Nucleofector solution and pre-loaded FI-115 or EO-115 pulse program (as indicated later) as recommended by the manufacturer for human T cells.

\section{Delivery of green fluorescent protein $m R N A, C A R$ mRNA and RNP complexes}

Green fluorescent protein (GFP) mRNA and CD19 CAR mRNA (TriLink BioTechnologies, San Diego, CA, USA) (see supplementary methods) were delivered to a final concentration of $2 \mu \mathrm{g} / 1 \times 10^{6}$ cells and $3.3 \mu \mathrm{g} / 1 \times 10^{6}$ cells respectively for both the Solupore system and electroporation. For co-delivery studies, $2 \mu \mathrm{g}$ of each mRNA was 
delivered. CD19 CAR expression was evaluated using a biotin-conjugated CD19 CAR detection reagent (Miltenyi Biotec) followed by streptavidin-phycoerythrin with 7-aminoactinomycin D as a viability stain. Cas9 (Integrated DNA Technologies, Coralville, IA, USA) was delivered at a final concentration of $3.3 \mu \mathrm{g} / 1 \times 10^{6}$ cells and precomplexed with a 2-M excess of guide RNA (gRNA) (2.48 $\mu$ M Cas9 and $4.96 \mu \mathrm{M}$ gRNA; Integrated DNA Technologies). The sequence for human $\mathrm{T}$ cell receptor alpha constant (TRAC)-targeting gRNA was AGAGTCTCTCAGCTGGTACA and the sequence for human CD7-targeting gRNA was GGAGCAGGTGATGTTGACGG. Expression of CD3 and CD7 (antibody clone CD7-6B7; BioLegend, San Diego, CA, USA) was analyzed by flow cytometry.

\section{Flow cytometry analysis}

Flow cytometry was performed using a NovoCyte 3000 (ACEA Biosciences, San Diego, CA, USA). Data were examined using NovoExpress software (ACEA Biosciences).

\section{Proliferation assay}

Following transfection with GFP mRNA, T cells were counted using an NC-Slide A8 and Solution 13 on the NucleoCounter NC-3000 according to the manufacturer's protocol. Samples were adjusted to a viable cell density of $1 \times 10^{6}$ cells $/ \mathrm{mL}$ and $200 \mu \mathrm{L}$ was transferred to a U-bottom 96-well plate (Greiner, Kremsmünster, Austria). Cells were placed in a humidified $37^{\circ} \mathrm{C}, 5 \%$ carbon dioxide $\left(\mathrm{CO}_{2}\right)$ incubator for $72 \mathrm{~h}$. Samples were then counted, reseeded at a viable cell density of $1 \times 10^{6}$ cells $/ \mathrm{mL}$ in fresh medium and incubated for a further $96 \mathrm{~h}$. Projected cell growth over 7 days was calculated by multiplying a starting cell number of $5 \times 10^{6}$ viable cells by the observed fold growth over 3 days. This value was then multiplied by the observed fold growth over the following 4 days.

\section{Gene profiling}

Resting $\mathrm{T}$ cells were transfected in the absence of cargo and RNA was isolated from cells using the RNeasy mini kit (Qiagen, Hilden, Germany) as per the manufacturer's instructions. Transcripts were analyzed using the nCounter human CAR Tcell characterization panel (NanoString, Seattle, WA, USA). Differential expression was displayed using $>\log 2$ fold change ( $>2$-fold linear change) with tables filtered $-1 \geq \log 2 \leq 1$.

\section{In vitro cytotoxicity assays}

At $24 \mathrm{~h}$ post-delivery of CD19 CAR mRNA, cells were cryopreserved in CryoStor CS10 (Sigma-Aldrich, St Louis, MO, USA). In vitro cytotoxicity was measured with an impedance assay using the xCELLigence real-time cell analyzer single plate instrument (ACEA Biosciences). Wells of the electronic microtiter plates were coated with $4 \mu \mathrm{g} / \mathrm{mL}$ CD40 (ACEA Biosciences) for $3 \mathrm{~h}$. Raji cells (American Type Culture Collection, Manassas, VA, USA) were seeded at $5 \times 10^{4}$ cells/ well and allowed to adhere overnight. At 19-21 h later, CAR T cells were thawed and added to the Raji cells at E:T ratios of 2.5:1, 1.25:1, $0.6: 1$ and $0.1: 1$. Impedance was monitored every $1 \mathrm{~min}$ for $4 \mathrm{~h}$, every $5 \mathrm{~min}$ for $8 \mathrm{~h}$ and then every $15 \mathrm{~min}$ for at least $92 \mathrm{~h}$. Cell indexes were normalized to a cell index of the time point when CAR T cells were added and specific lysis was calculated in comparison with control effector cell-only cultures.

In vivo murine CAR T-cell efficacy study

CD19 CAR mRNA was delivered to T cells and cells were cryopreserved. NOD $/ \mathrm{SCID} / \gamma^{-1-}$ mice were engrafted on day 0 with CD19+ Raji-luciferase tumor cells $\left(2.5 \times 10^{5}\right.$ cells $)$ intravenously, and mice were then randomized across treatment groups based on body weight. On day 3, CAR T cells were thawed and $1 \times 10^{6}$ cells, $2 \times 10^{6}$ cells or $4 \times 10^{6}$ cells were injected per animal. On day 15 , bioluminescence imaging was carried out, animals were euthanized by $\mathrm{CO}_{2}$ asphyxiation and blood was taken for analysis. HuCD3 V605 clone UCHT1 antibody (BioLegend) and BD FACSDiva software (BD Biosciences, San Jose, CA, USA) were used for flow cytometry analysis.

\section{Statistics}

A Wilcoxon matched-pairs signed-rank test was carried out on the cell proliferation data. The gene expression analysis was carried out by NanoString using their nSolver software. CD19 CAR expression and CAR T-cell in vivo engraftment were analyzed using a two-tailed paired t-test.

\section{Results}

\section{Efficient and versatile engineering of primary human T cells}

Next-generation immune cell therapies will require complex editing that may include the addition and deletion of cell functions. Therefore, the ability of the Solupore system to both introduce functionality to $\mathrm{T}$ cells using mRNA and delete functionality using CRISPR-Cas9 gRNA RNP complexes was determined. To further examine the versatility of the platform, these cargos were delivered in combination or sequentially. GFP mRNA was delivered to $T$ cells from three donors and GFP expression and cell viability were examined at $24 \mathrm{~h}$ post-transfection. GFP expression was greater than $80 \%$ in each donor, with high cell viability retained (Figure 1A). The proliferation of $\mathrm{T}$ cells following delivery of GFP mRNA remained similar to that of untreated cells (Figure 1B). When CAR mRNA was co-delivered with GFP mRNA, more than $57 \%$ of the population was $\mathrm{GFP}^{+} / \mathrm{CAR}^{+}$at $24 \mathrm{~h}$ post-transfection, again with high cell viability retained (Figure 1C). CRISPR-Cas9 RNP complexes targeting the TRAC and CD7 genes were delivered to $T$ cells individually and sequentially. When delivered individually, CD3 and CD7 expression in the treated populations was reduced to approximately 25\% in both cases (Figure 1D). When TRAC RNP was delivered and was followed 2 days later by CD7 RNP, approximately $5 \%$ of the treated population retained a $\mathrm{CD}^{+} /$ $\mathrm{CD}^{+}$phenotype, and viability remained high when examined 4 days post-delivery of CD7 RNP (Figure 1D).

\section{Immune gene expression profiling demonstrates minimal cell perturbation}

The cargo delivery studies demonstrated that transfection with the Solupore system was efficient while having minimal effect on cell viability and proliferation. However, it has been reported that although delivery methods such as electroporation can minimally affect $T$ cell viability, accompanying stress to cells can cause unintended changes to gene expression and, ultimately, cell functionality [8]. The authors therefore examined the effect of transfection on immune gene expression in T cells and included an electroporation comparator. The NanoString CAR T-cell characterization panel, which measures the gene expression of up to 780 immune-related genes, including genes relevant to immune cell exhaustion, activation and persistence, was used. It has previously been reported by DiTommaso et al. [8] that electroporation can dramatically affect gene expression in T cells. To align with that study, the same FI-115 "high-efficiency" electroporation program, as recommended by the manufacturer for $\mathrm{T}$ cells, was used here. Also in alignment with the previous study, unstimulated $\mathrm{T}$ cells were mock transfected to avoid potential confounding effects of cargo on gene expression.

In the first of these studies (study 1 ), $\mathrm{T}$ cells from three donors, each including two technical repeats, were mock transfected. Gene 


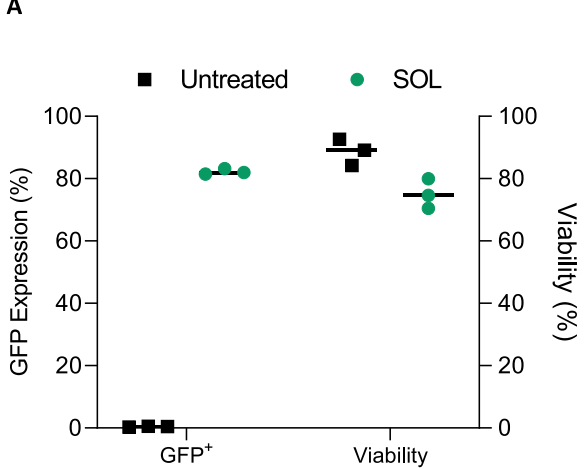

C Untreated

- SOL

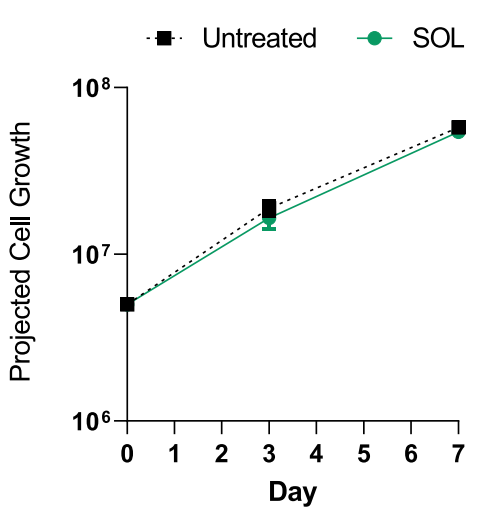

D

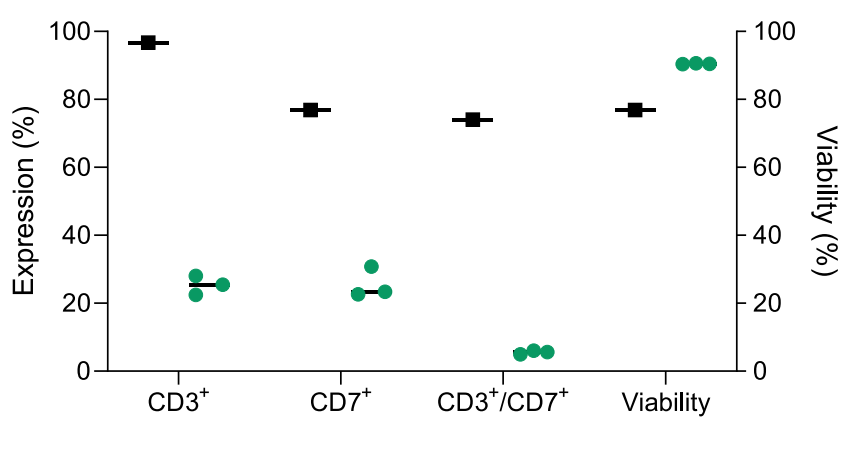

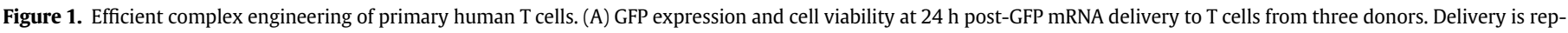

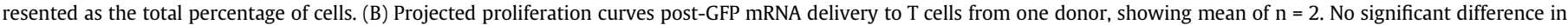

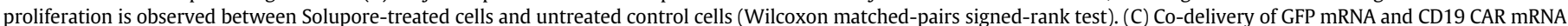

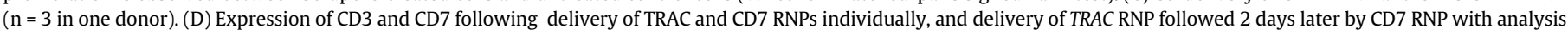
at day 5 post-CD7 RNP delivery ( $\mathrm{n}=3$ in one donor). SOL, Solupore system. (Color version of figure is available online).

expression was analyzed at $6 \mathrm{~h}$ and $24 \mathrm{~h}$ post-transfection. In cells treated using the Solupore system, $1.7 \%$ of genes at the 6 -h time point were identified as differentially expressed compared with untreated control cells (10 of 582 genes, $>\log 2$ fold change , $P<0.05$, dataset S1). At 24 h post-transfection, no changes in gene expression were identified ( 0 of 582 genes). By contrast, for the electroporation 6-h group, 265 of 582 genes were identified as changed, representing $45.5 \%$ of the genes detected (dataset S1). In the electroporation 24-h group, $11.3 \%$ of genes were differentially expressed (66 of 582 genes, dataset S2). Of the differentially expressed genes in the electroporation samples, 37 were expressed at both the $6 \mathrm{~h}$ and $24 \mathrm{~h}$ time points (see supplementary Table 1 ). Of the 10 genes identified in the Solupore system 6 -h group, eight were also identified in the electroporation 6-h group (see supplementary Table 2 ). To provide an overview of differentially expressed genes, volcano plots (Figure 2A) and heat maps (Figure 2B; also see supplementary Figure 1) were generated and illustrated the impact of electroporation on gene expression in $\mathrm{T}$ cells. A pathway analysis was also completed (Table 1 ; also see supplementary Figure 2) and showed that a majority of the genes identified in the electroporation 6-h group mapped to pathways associated with T-cell activation, metabolism and exhaustion.

To expand upon these findings, a second study was carried out with gene expression analysis at $24 \mathrm{~h}$ post-transfection. Each group included unstimulated $\mathrm{T}$ cells, with two donors run in technical duplicate and a third donor as a single sample, and all were mock transfected. The results were similar to those seen in the first study, with only nine of 597 genes (1.5\%) identified in cells treated with the Solupore system and 43 of 597 genes (7.2\%) identified for the electroporation group (dataset S3), showing consistency with the first study. Four genes were identified as being in common between the two transfection systems used in this study (see supplementary Table 3 ). When both studies were compared, 38 genes were found to be common between the 24 -h electroporation groups, again showing consistency between the studies (Table 2).

\section{Generation of CD19 CAR T cells and in vitro and in vivo cytotoxicity}

The Solupore system was next used to generate CAR T cells cancer cell killing in vitro and in vivo was examined. An electroporation comparison was also carried out. As noted, the FI-115 program was used for the gene expression profiling study above to enable comparison with data published by another group [8]. However, the EO-115 program is widely used for primary T cellsand so was used for the CD19 CAR T-cell study here. CD19 CAR mRNA was delivered to T cells from three donors. CD19 CAR expression in Solupore cells ranged from $72 \%$ to $76 \%$ across the donors (Figure 3A). Although CD19 CAR expression was slightly higher in electroporated cells, this was not statistically significant (two-tailed paired $t$-test). In vitro cytotoxicity against CD19-expressing Raji cells was determined using a real-time cellular impedance assay. CAR T cells from each donor showed efficient levels of cytotoxicity against the target Raji cells that were comparable for both Solupore and electroporated cells (Figure 3A). 
A

$6 \mathrm{~h}$

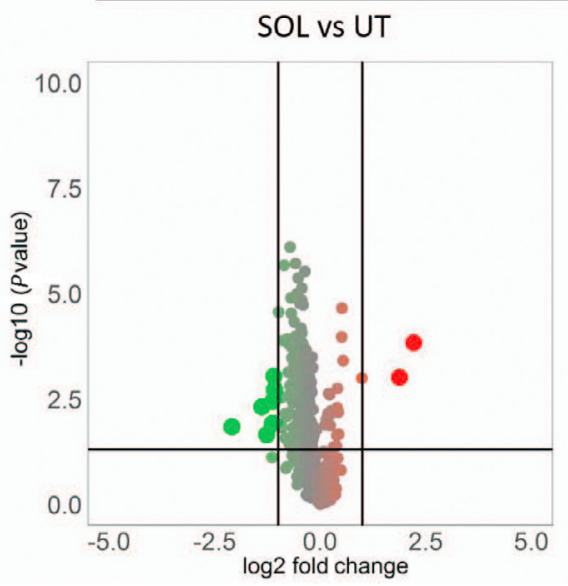

EP Vs UT

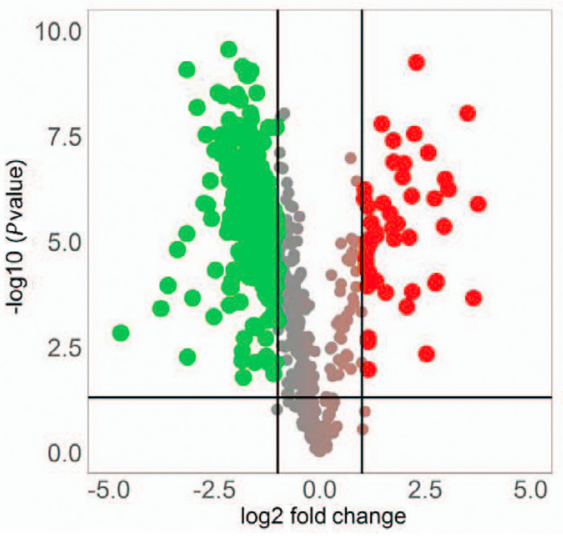

$24 \mathrm{~h}$

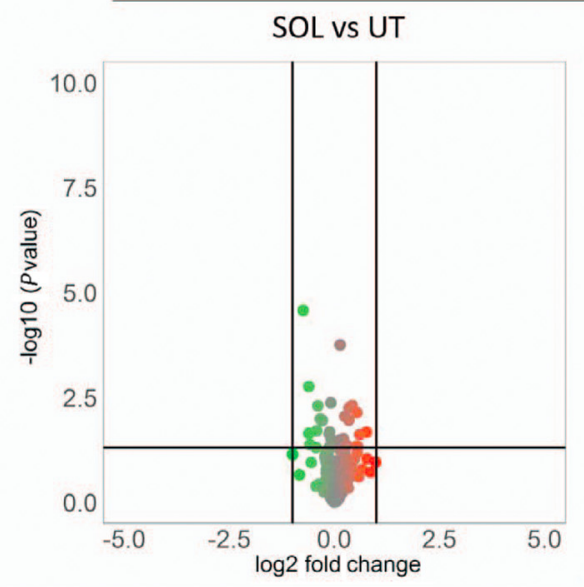

B

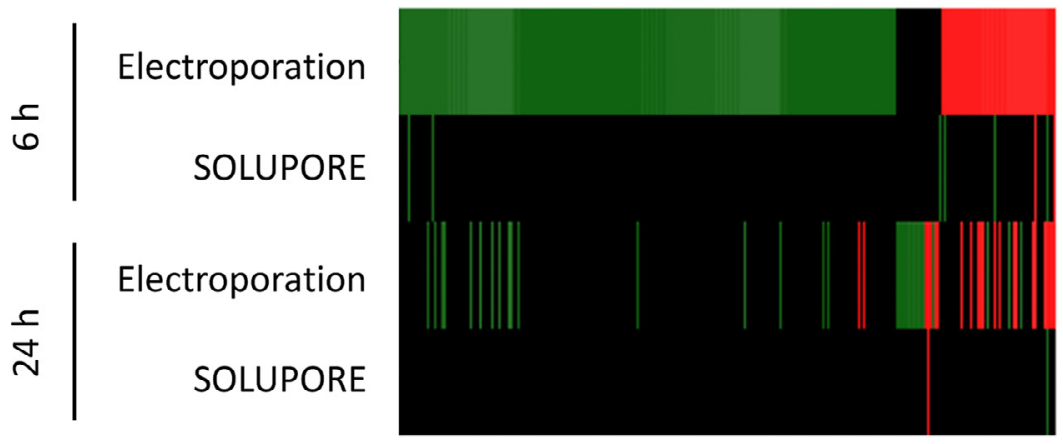

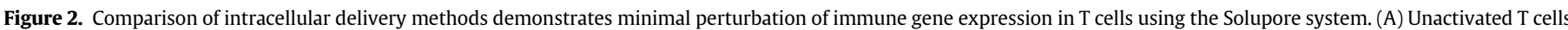

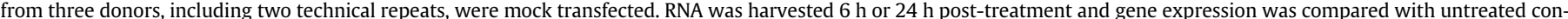

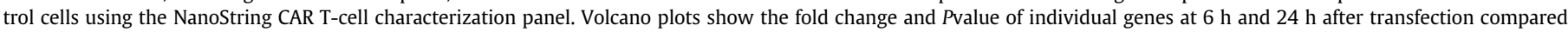

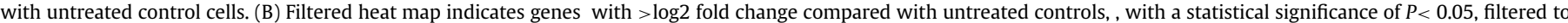

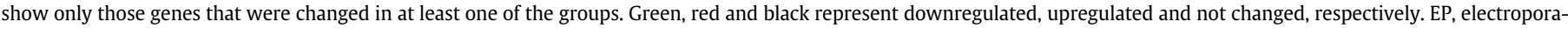
tion; SOL, Solupore system; UT, untreated.

The therapeutic potential of these CD19 CAR T cells was evaluated in vivo using a luciferase-expressing Raji tumor model in immunodeficient NOD $/ \mathrm{SCID} / \gamma^{-1-}$ mice (Figure 3B). Mice received doses of $1 \times 10^{6}$ CAR T cells, $2 \times 10^{6}$ CAR T cells or $4 \times 10^{6}$ CAR T cells, and disease progression was monitored by bioluminescent imaging. At 12 days following dosing, reduced tumor growth was 
Table 1

Pathway analysis of genes identified at $6 \mathrm{~h}$ in CAR T cell characterization panel.

\begin{tabular}{lll}
\hline Gene pathway & $\begin{array}{l}\text { Associated genes } \\
\text { identified in } \\
\text { electroporation group, } \mathrm{n}\end{array}$ & $\begin{array}{l}\text { Associated genes } \\
\text { identified in Solupore } \\
\text { system group, } \mathrm{n}\end{array}$ \\
\hline Activation & 77 & 4 \\
Metabolism & 56 & 2 \\
Exhaustion & 49 & 2 \\
TCR signaling & 25 & 3 \\
Apoptosis & 22 & 1 \\
Chemokine signaling & 15 & 1 \\
T-cell migration and & 11 & 0 \\
$\quad$ persistence & 8 & 0 \\
Glycolysis & 6 & 0 \\
Antigen processing and & & \\
presentation & &
\end{tabular}

TCR, T cell receptor.

evident in a dose-dependent manner in cohorts that had received either Solupore CAR T cells or cells generated using electroporation (Figure 3C). It was notable that three of 10 mice appeared diseasefree in the group that received the highest dose of Solupore CAR T cells. There were also significantly higher numbers of Solupore CAR $\mathrm{T}$ cells in the blood of those mice that received the $2 \times 10^{6}$ Solupore CAR T cells and $4 \times 10^{6}$ Solupore CAR T cells compared with their electroporation counterparts $(P<0.05$, two-tailed paired $t$-test $)$, indicating higher levels of CAR T-cell engraftment in those animals (Figure 3D).

Table 2

Comparison of electroporation groups (24-h time point) in study 1 and study 2 showing common genes identified with $>\log 2$ fold change, $P<0.05$.

\begin{tabular}{|c|c|c|}
\hline Gene & $\begin{array}{l}\text { Study } 1 \text { (log } 2 \text { fold } \\
\text { change) }\end{array}$ & $\begin{array}{l}\text { Study } 2 \text { (log } 2 \text { fold } \\
\text { change) }\end{array}$ \\
\hline$A H R$ & 1.38 & 1.29 \\
\hline BATF & 1.38 & 1.23 \\
\hline BATF3 & 2.93 & 2.05 \\
\hline CCL22 & 4.21 & 2.09 \\
\hline CCL4/L1 & -1.71 & -1.42 \\
\hline CD19 & 1.57 & 1.58 \\
\hline CD200 & 1.93 & 2.92 \\
\hline$C D 244$ & -1.31 & -2.26 \\
\hline CD38 & 2.93 & 2.33 \\
\hline CD68 & 1.09 & 1.85 \\
\hline CTSW & -1.87 & -1.64 \\
\hline CXЗCR1 & -2.68 & -2.12 \\
\hline$F C G R 3 A / B$ & -2.54 & -1.4 \\
\hline FOS & 1.84 & 1.82 \\
\hline$F O S B$ & 3.23 & 2.82 \\
\hline GZMA & -1.66 & -1.36 \\
\hline GZMH & -1.8 & -1.08 \\
\hline GZMK & -1.68 & -1.54 \\
\hline ICOSLG & 1.21 & 1.27 \\
\hline IFIT3 & 1.92 & 1.99 \\
\hline IL12RB2 & 1.83 & 1.46 \\
\hline IL7R & -1.34 & -1.04 \\
\hline IRF4 & 2.37 & 1.81 \\
\hline IRF8 & 2.28 & 1.94 \\
\hline ITGAM & -1.86 & -1.64 \\
\hline JUN & 2.34 & 1.96 \\
\hline KLRB1 & -1.55 & -1.23 \\
\hline LAIR1 & -1.66 & -1.2 \\
\hline$M T 2 A$ & 1.39 & 1.14 \\
\hline NCR1 & -1.72 & -1.28 \\
\hline NFIL3 & 1.01 & 1.11 \\
\hline NT5E & -1.43 & -1.22 \\
\hline PRF1 & -1.46 & -1.14 \\
\hline SELL & -1.19 & -1.05 \\
\hline TIMP1 & -1.43 & -1.42 \\
\hline TRGC2 & -1.27 & -1.03 \\
\hline TRGV2 & -1.45 & -1.12 \\
\hline TYROBP & -1.39 & -1.4 \\
\hline
\end{tabular}

\section{Discussion}

Challenges with current approaches to cell therapy development and manufacture have led to the expectation that virus-free protocols will play a key role in the development of next-generation products [18-20]. The Solupore system has been developed as an advanced non-viral technology aimed at addressing some of these challenges, and here we have demonstrated the delivery efficiency of the system with a range of cargo types.

The ability of the platform to support multiplex delivery and sequential gene edits without compromising cell viability is an important feature. If targeting and efficacy are to be enhanced in autologous cell therapies for both liquid and solid tumors, cells will require multiplex or sequential engineering steps that can integrate with manufacturing processes. Limitations in viral vector capacity and electroporation toxicity mean that these modalities may be unsuitable for many complex engineering regimes. The studies reported here demonstrate that the Solupore transfection process has a minimal impact on gene expression in T cells and, importantly, biological attributes such as viability and proliferation are preserved. Moreover, CAR T-cell killing in vitro and in vivo demonstrates the functionality of these cells.

Although electroporation is currently the most widely used nonviral method for cargo delivery, non-specific changes in protein and gene expression and reduced anti-tumor efficacy in $\mathrm{T}$ cells engineered by this method have been reported previously [7]. The data here correlate well with that report. In the gene expression profiling study carried out here, the Solupore process resulted in the altered expression of only a small number of immune-related genes. Of the 10 genes identified in the 6-h group, eight were found to be in common with the electroporation 6-h group, suggesting that these may be genes associated with breaching of the cell membrane or other processes common to the two delivery methods. It is noted that gene expression was examined at early time points in the study and might be different following a standard 1-week ex vivo expansion. Nonetheless, the finding that electroporation dramatically affects gene expression in $\mathrm{T}$ cells is consistent with the aforementioned previous study as well as with another report of increased levels of intracellular calcium and transcriptional activity in electroporated T cells in the absence of exogenous stimuli [13]. Others have also found that electroporation leads to reduced cell proliferation, with data suggesting that this is caused by activation of DNA damage response pathways [21]. This is a concern for gene editing approaches, and it is unclear how these effects of electroporation will ultimately impact the potency of cell therapy products.

There is also increasing interest in the possibility of engineering unactivated $\mathrm{T}$ cells to reduce the likelihood of effector cell exhaustion. In this scenario, unactivated cells could be engineered and subsequently expanded. This would have the added advantage of requiring substantially less cargo. The finding in this and other studies that electroporation induces perturbations in unactivated $\mathrm{T}$ cells at the transcriptional level makes it a less desirable approach for this application. By contrast, the Solupore system has the potential to enable engineering of these cells, allowing for the manufacture of both unactivated and activated complex engineered cells with minimal perturbation to cell functionality.

The Solupore system is well placed to address several cell therapy development and manufacturing challenges. The long lead time required to design and generate even research-grade viral vectors means that timelines may be longer than desired at the cell therapy development stage. This is of particular concern in relation to progressing novel approaches for solid tumors where targeting and efficacy challenges mean that large numbers of candidate target antigens and cell potency enhancements will need to be tested. It will be necessary to evaluate a myriad of cell compositions in a 
rapid, high-throughput fashion that is likely to be highly constrained if wholly reliant on viral vectors. The studies reported here show that the Solupore system is compatible with the acceleration of the innovation cycle time required for impactful progress in tackling solid tumors. Because the process is gentle on cells compared with electroporation, the initial yield in the number of viable, transgene-positive cells is likely to be higher. This would positively impact manufacturing feasibility, with benefits for cost and the ability to successfully produce a final product to treat patients. Another manufacturing consideration is the simplicity of the Solupore process and the low number of steps. Unlike electroporation, the same Solupore programs and buffers can be used for a range of cell types, with cell density being the main parameter that is varied. In addition, the cells do not require a buffer change prior to transfer into the Solupore system, meaning that the process is shorter and less complex, which is highly desirable in the context of cell therapy manufacture. The Solupore technology is currently being developed to address clinically meaningful cell numbers, in the range of $10^{8}$ cells, in a current GMP-aligned format and will be licensed to cell therapy developers and contract development and

A
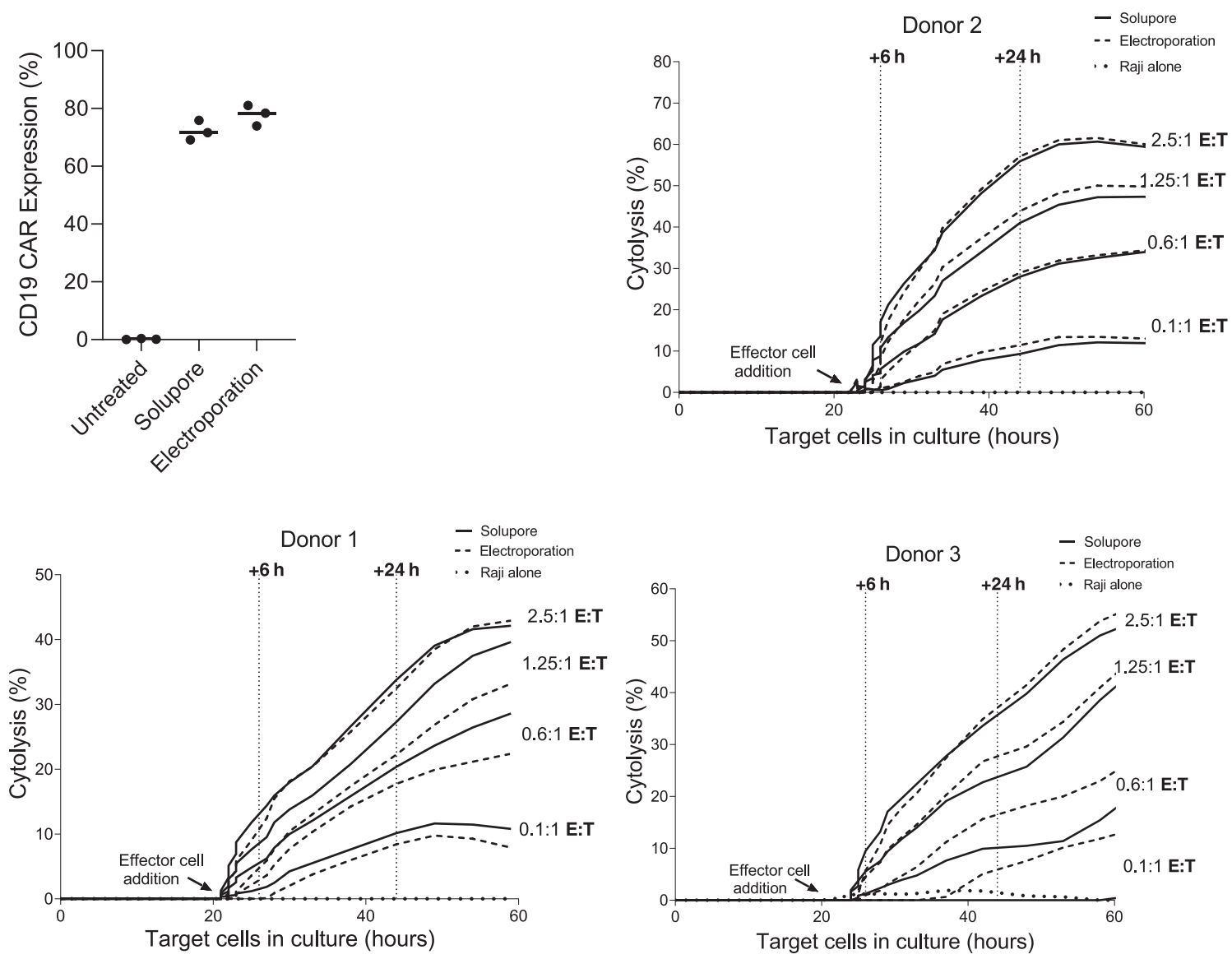

B

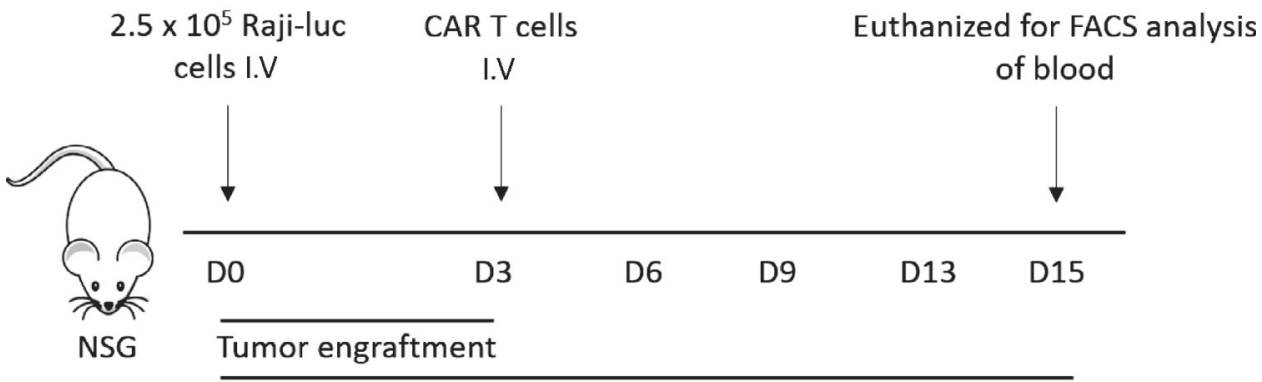

IVIS BLI

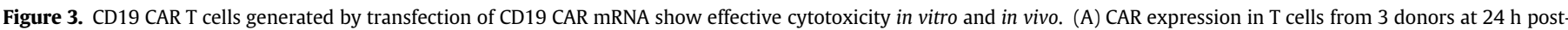

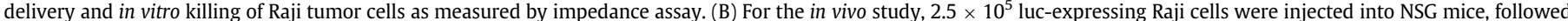

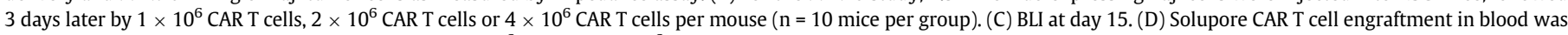

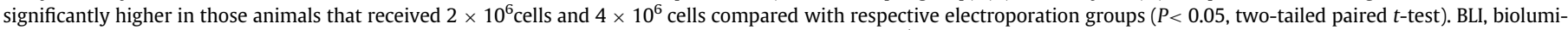
nescence imaging; D, day; FACS, fluorescence-activated cell sorting; IV, intravenous; NSG, NOD/SCID $/ \gamma^{-1-}$; Raji-luc, Raji-luciferase. 
C

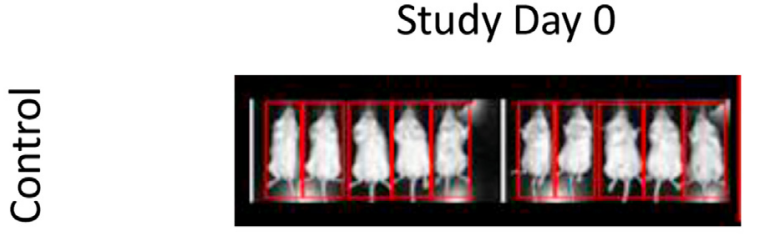

Study Day 15
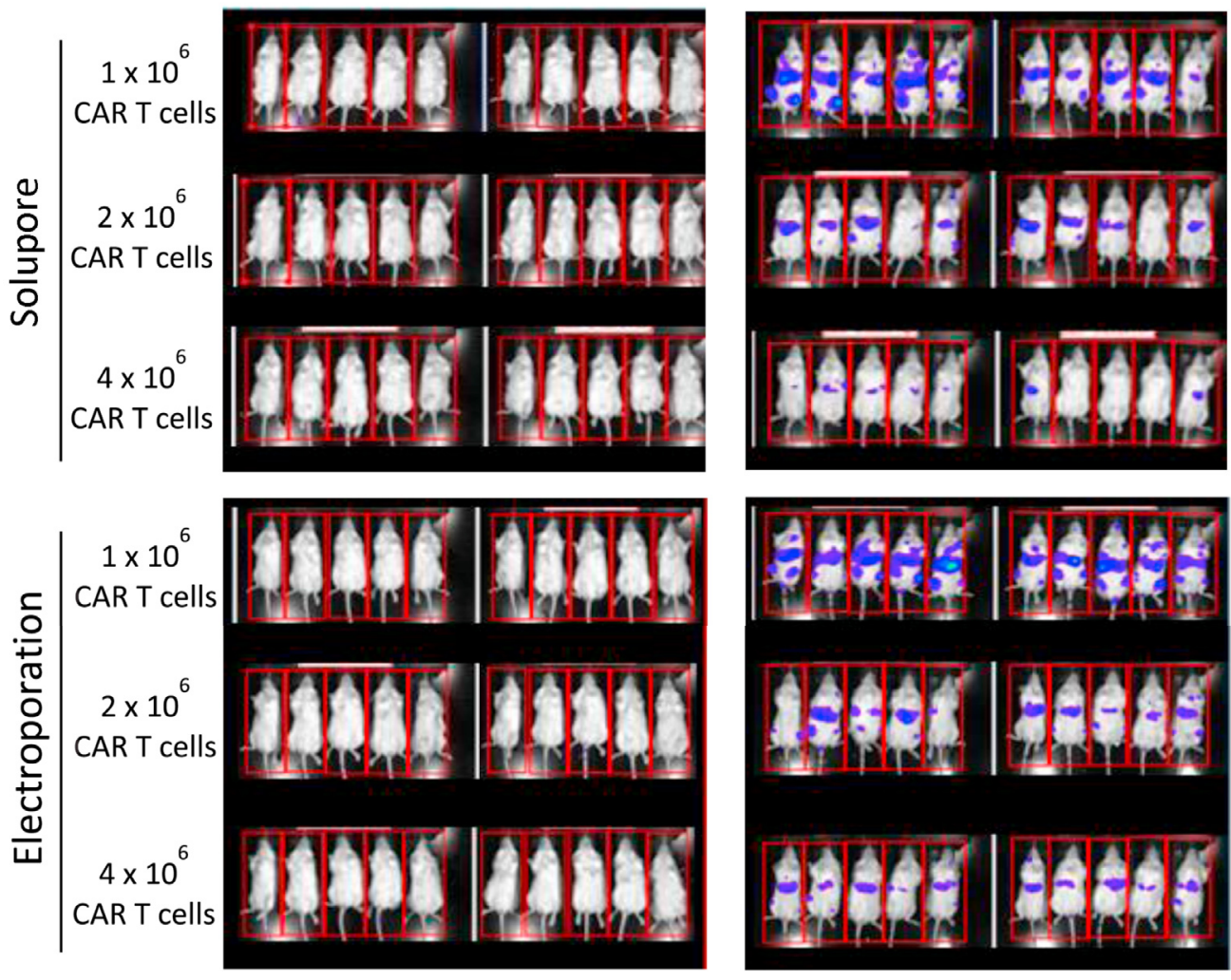

D
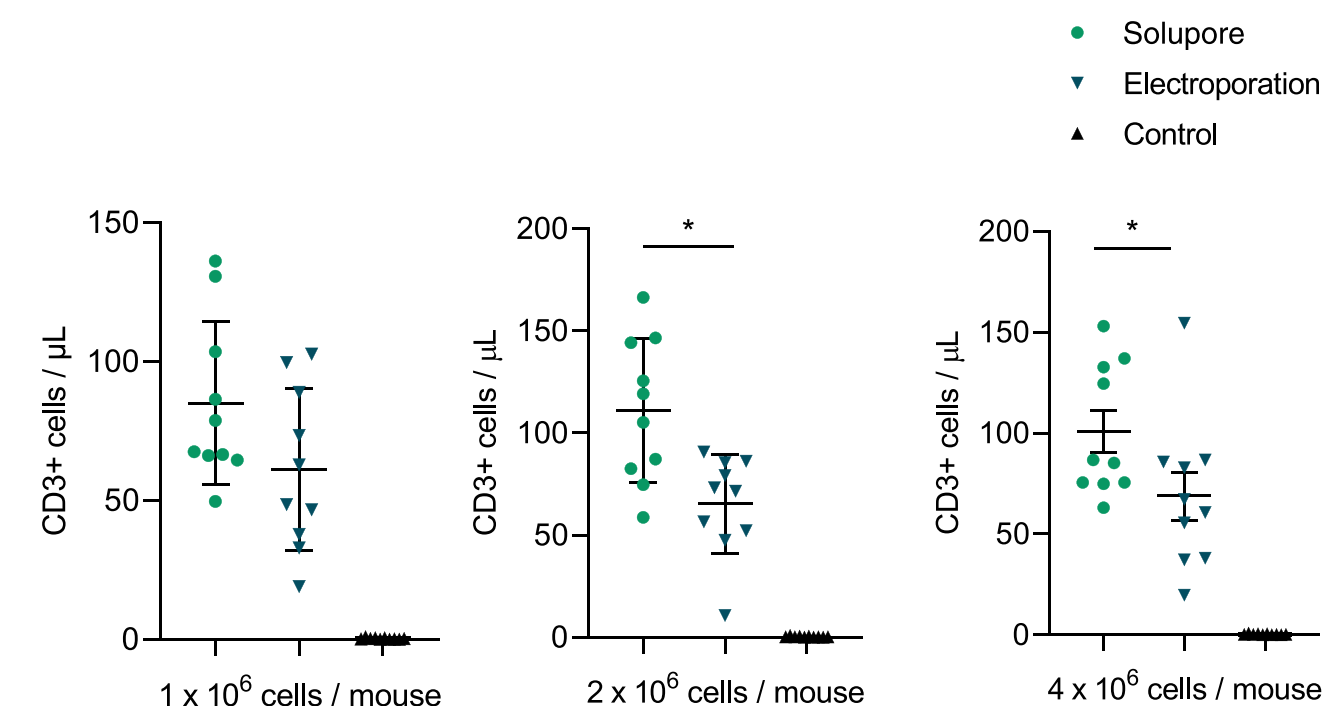

Figure 3. Continued.

- Solupore

- Electroporation

- Control 
manufacturing organizations, where it will integrate into manufacturing processes. A flow-through version of the technology that can address even higher numbers of cells is also in the early stages of development.

\section{Conclusions}

The authors have demonstrated that the Solupore system represents an attractive non-viral delivery platform that efficiently engineers $\mathrm{T}$ cells while retaining high levels of cell viability and functionality and possesses many features that are well suited to addressing the manufacturing challenges of next-generation cell therapy products.

\section{Funding}

This study was funded by the European Research Council (grant no. 811360, Solupore, H2020-EIC-SMEInst-2018-2020/H2020SMEInst-2018-2020-2) and by Avectas Ltd.

\section{Declaration of Competing Interest}

All authors are or were employees of Avectas Ltd during the course of this work. SOD is a shareholder in Avectas Ltd.

\section{Author Contributions}

Conception and design of the study: SOD and HK. Acquisition of data: SD, DM, EM, LG and SL. Analysis and interpretation of data: HK, SD, DSM, EM, LG, JS, SL and SO. Drafting or revising the manuscript: SOD, HK, SD, DM and JS. All authors have approved the final article.

\section{Supplementary materials}

Supplementary material associated with this article can be found in the online version at doi:10.1016/j.jcyt.2021.03.002.

\section{References}

[1] Ahmad A, Uddin S, Steinho M. CAR T cell therapies: an overview of clinical studies supporting their approved use against acute lymphoblastic leukemia and large Bcell lymphomas. Int J Mol Sci 2020;21:3906.

[2] Levine B, Miskin J, Wonnacott K, Keir C. Global Manufacturing of CAR T Cell Therapy. Mol Ther 2017;4:92-101.

[3] David R, Doherty A. Viral Vectors: The road to reducing genotoxicity. Toxicol Sci 2017:155:315-25

[4] Rafiq S, Hackett C, Brentjens R. Engineering strategies to overcome the current roadblocks in CAR T cell therapy. Nat Rev Clin Oncol 2020;17:147-67.

[5] Stewart M, Sharei A, Ding X, Sahay G, Langer R, Jensen K. In vitro and ex vivo strategies for intracellular delivery. Nature 2016;538:183-92.
[6] Stewart M, Langer R, Jensen K. Intracellular delivery by membrane disruption: mechanisms, strategies, and concepts. Chem Rev 2018:118:7409-531.

[7] Bono N, Ponti F, Mantovani D, Candiani G. Non-viral in vitro gene delivery: it is now time to set the bar. Pharmaceutics 2020;12:183.

[8] DiTommaso T, Cole J, Cassereau L, Buggé J, Sikora Hanson J, Bridgen D, Stokes B Loughhead S, Beutel B, Gilbert J, Nussbaum K, Sorrentino A, Toggweiler J, Schmidt T, Gyuelveszi G, Bernstein H, Sharei A. Cell engineering with microfluidic squeezing preserves functionality of primary immune cells in vivo. Proc Natl Acad Sc USA 2018;115:E10907-14.

[9] Azarnezhad A, Samadian H, Jaymand M, Sobhani M, Ahmadi A. Toxicological profile of lipid-based nanostructures: are they considered as completely safe nanocarriers? Crit Rev Toxicol 2020;50:148-76.

[10] Olden BR, Cheng Y, Yu JL, Pun SH. Cationic polymers for non-viral gene delivery to human T cells. J Control Release 2018;282:140-7.

[11] Harris E, Zimmerman D, Warga E, Bamezai A, Elmer J. Nonviral gene delivery to T cells with Lipofectamine LTX. Biotech Bioeng 2021;118:1693-706.

[12] Stadtmauer E, Fraietta J, Davis M, Cohen A, Weber K, Lancaster E, Mangan P, Kulikovskaya I, Gupta M, Chen F, Tian L, Gonzalez V, Xu J, Jung I, Joseph Melenhorst J Plesa G, Shea J, Matlawski T, Cervini A, Gaymon A, Desjardins S, Lamontagne A, Salas-Mckee J, Fesnak A, Siegel D, Levine B, Jadlowsky J, Young R, Chew A, Hwang W, Hexner E, Carreno B, Nobles C, Bushman F, Parker K, Qi Y, Satpathy A, Chang $\mathrm{H}$, Zhao Y, Lacey S, June C. CRISPR-engineered T cells in patients with refractory cancer. Science 2020;367: eaba7365.

[13] Zhang M, Ma Z, Selliah N, Weiss G, Genin A, Finkel T, Cron R. The impact of nucleofection on the activation state of primary human CD4 T cells. J Immunol Methods 2014;408:123-31.

[14] Beane J, Lee G, Zheng Z Mendel M, Abate-Daga D, Bharathan M, Black M, Gandh N, Yu Z, Chandran S, Giedlin M, Ando D, Miller J, Paschon D, Guschin D, Rebar E, Reik A, Holmes M, Gregory P, Restifo N, Rosenberg S, Morgan R, Feldman S. Clinical Scale Zinc Finger Nuclease-mediated Gene Editing of PD-1 in Tumor Infiltrating Lymphocytes for the Treatment of Metastatic Melanoma. Mol Ther 2015;23:1380-90.

[15] Ghassemi S, Nunez-Cruz S, O'Connor R, Fraietta J, Patel P, Scholler J, Barrett D, Lundh S, Davis M, Bedoya F, Zhang C, Leferovich J, Lacey S, Levine B, Grupp S, June C, Melenhorst J, Milone M. Reducing ex vivo culture improves the antileukemic activity of chimeric antigen receptor (CAR) T cells. Can Immunol Res 2018;6: 1100-9.

[16] Finney O, Brakke H, Rawlings-Rhea S, Hicks R, Doolittle D, Lopez M, Futrell B, Orentas R, Li D, Gardner R, Jensen M. CD19 CAR T cell product and disease attributes predict leukemia remission durability. J Clin Invest 2019;129: 2123-32.

[17] O'Dea S, Annibaldi V, Gallagher L, Mulholland J, Molloy E, Breen C, Gilbert J, Martin D, Maguire M, Curry F. Vector-free intracellular delivery by reversible permeabilization. PLoS One 2017;12:e0174779.

[18] Freitag F, Maucher M, Riester Z, Hudecek M. New targets and technologies for CAR-T cells. Curr Opin Oncol 2020;32:510-7.

[19] Namuduri M, Brentjens RJ. Enhancing CAR T cell efficacy: the next step toward a clinical revolution? Expert Rev Hematol 2020;13:533-43.

[20] Roth T, Puig-Saus C, Yu R, Shifrut E, Carnevale J, Li P, Hiatt J, Saco J, Krystofinski P, Li H, Tobin V, Nguyen D, Lee M, Putnam A, Ferris A, Chen J, Schickel J, Pellerin L, Carmody D, Alkorta-Aranburu G, Del Gaudio D, Matsumoto H, Morell M, Mao Y, Cho M, Quadros R, Gurumurthy C, Smith B, Haugwitz M, Hughes S, Weissman J, Schumann K, Esensten J, May A, Ashworth A, Kupfer G, Greeley S, Bacchetta R, Meffre E, Roncarolo M, Romberg N, Herold K, Ribas A, Leonetti M, Marson A. Reprogramming human $\mathrm{T}$ cell function and specificity with non-viral genome targeting. Nature 2018;559:405-9.

[21] Livingston P, Strouse B, Perry H, Borjigin M, Bialk P, Kmiec E. Oligonucleotide delivery by nucleofection does not rescue the reduced proliferation phenotype of gene-edited cells. Nuc Acid Ther 2012;22:405-13. 